arrive at a figure nearly as good as that of the matrix, of rather greater focal length, it may be, but nearly equally lengthened in all its parts.

Birr Castle, Parsonstown, August 14.

\section{The Form of a Dirigible Balloon.}

Although it is not likely that dirigible balloons will be of much practical value except for purposes of amusement and to a limited extent for military observations, it seems a pity that the designs of such as are made should not embody existing knowledge as to the conditions which govern the resistance and stability of submerged bodies.

The resistance of a submerged body is a far less complex quantity than the resistance of a ship (inasmuch as no question of surface waves is involved), and can be stated simply as the sum of the resistances due to surface friction and wake, both of which vary very nearly as the square of the speed.

The surface friction resistance cannot be reduced below a certain limit, for the surface exposed cannot be less than the surface of a sphere which will hold the required volume of gas.

The wake or eddy-making resistance can, however, be very largely reduced by giving the balloon a shape gently tapering towards the stern, a shape which is adopted by all animals (birds, fish, whales, seals, \&c.) the habits of which require them to move rapidly as submerged bodies.

The shape of the head of the balloon does not matter much so long as the profile is a fair curve. The important thing for reducing the wake is that from some position in front of the maximum diameter of the balloon the radius of curvature of the profile should increase, slowly at first, but continuousiy, towards the stern.

With regard to stability, it should be borne in mind that

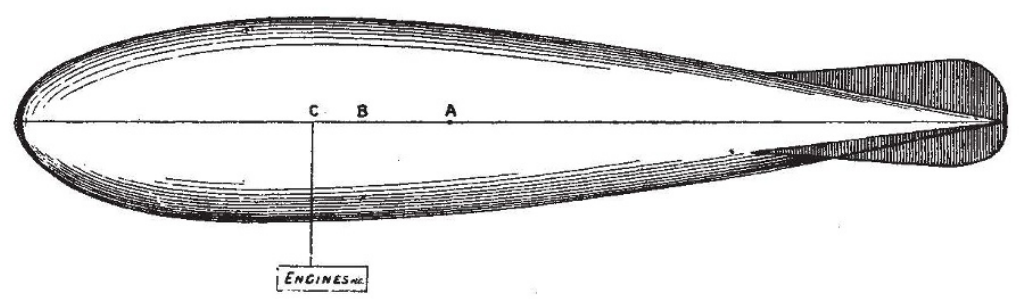

A, Centre of gravity of balloon. B, Centre of buoyancy of balloon. lighter engines, and I think that perhaps the most valuable part of Count Zeppelin's work has been to show that it is practicable to construct a balloon the shape of which is moulded by internal frames.

6. Cresswell Gardens, S.W., August 12.

\section{The "Sky-coloured Clouds" or Twilight Glows.}

There can, I think, be no doubt that the numerous descriptions which have appeared of the recent twilight phenomena relate to essentially the same phenomenon as the "sky-coloured clouds," or, as the late O. Jesse called them, the "luminous night-clouds." On June $3^{\circ}$ and July $\mathrm{I}$, which seem to have been the principal dates, I was unfavourably situated for observing the phenomenon, but I may point out that I directed attention to it in your issue of June II, p. I27.

The displays that have been noted in former years have been marked by a very striking appearance as of cirrus clouds, only (as $O$. Jesse ascertained) at a much greater altitude, viz, fifty-one miles. From the descriptions this year the cirrus-like appearance has evidently not been so well marked, although it is mentioned by some observers, and I noticed it myself (partly here and partly in Scotland); but sometimes the aspect of the light was uniform, and not striated like cirrus. In former years I have also sometimes observed the same when there was evidently a tendency to the formation, and yet the clouds did not appear, but only the luminosity. M. Fellix de Roy, in the Gazette Astronomique d'Anvers, No. 8, p. 63, is of opinion that this year the phenomenon was not the same as that investigated by $O$. Jesse, but he calls it an " extraordinary twilight." In either case, no doubt the cause is essentially the same-i.e. reflection-some substance being at such a height in the atmosphere that the sun can shine upon it when far below the horizon of the observer. The coloration, although varying in intensity on different occasions, is also the same in either case, viz. red or red-orange near the horizon, gradually changing through orange, yellow, and green to blue above. This is the ordinary coloration of a clear twilight sky, the difference between which and the recent phenomenon being mainly that of the height of the substance reflecting the sun's rays.

It has never been ascertained what the substance is, and it may be that in different years it has not been the same. This might account for the appearance this year being less like cirrus than formerly. It has been suggested that it may be meteoric dust.

Sunderland, August Ir.

\section{August Meteors of 1908 .}

The conditions this year were all against any bright or plentiful exhibition of the Perseids. Apart from the presence of the full moon, the sky at Bristol on August II and 12 was full of thin white clouds, amid which it was only possible to distinguish bright meteors. On August $\mathbf{r o}_{\mathbf{2}}$ however, the firmament was clear, but the Perseid shower was evidently influenced by the luminous atmosphere, for only about twelve per hour were visible before midnight. The radiant point was in the usual position at $43^{\circ}+57^{\circ}$. A few brilliant meteors were seen from Perseus on August ir, but clouds prevailed to such an extent that it was impossible to judge as to the strength of the display.

Mr. J. H. Elgie, of Leeds, had a clearer sky, and observed on August io and in a pretty numerous display of bright Perseids. Watching for an hour at about midnight on August ir, he saw twenty meteors. Reports from other places state that although some brilliant meteors were seen, they fell short in point of numbers with those observed in previous years in better circumstances. At Bristol the radiant point moved from $25^{\circ}+53^{\circ}$ on July 26 to $43^{\circ}+57^{\circ}$ on August ro. Watching was resumed early on the verv clear nights of August is and 16 , but meteors were found to be scarce, and the Perseid shower gave little sign of continued activity.
IV. F. Denning.

NO. 2025, VOL. 78$]$ 